Journal of Social Sciences 6 (1): 55-59, 2010

ISSN 1549-3652

(C) 2010 Science Publications

\title{
Developing a Paradigm for Describing Diversity and Multiculturalism in Modern America
}

\author{
Mary Beth Leidman and Bradley E. Wiggins \\ Department of Communications Media, Indiana University of Pennsylvania, \\ Indiana, Pennsylvania, USA
}

\begin{abstract}
Problem statement: There exists misconceptions about the roles and characteristics of diversity and multiculturalism is American Society. The definitions and interrelationships are skewed as there continue to exist unanswered questions about to what extent the society is multicultural. Approach: The objective is to illustrated and discussed a theoretical construct where it will be possible to define, examine and test specific variables that define cultural neighborhoods. A group of Defining Intracultural Traits (DITS) creates a clear picture of how diversity and multiculturalism remain distinct entities within the United State societies. The DITS variables include: Language, Food, Religion/Ideology, and Comfort with Customs Results: Models are introduced which show the force field relationships between cultural entities. This paradigm illustrates the opposing fields which prevent the free sharing of culture on anything but a superficial level. This position prevents anything but a casual sharing of cultures within public settings such as the workplace, schools and sports events. Conclusion: American society does not exhibit many of the characteristics of assimilation and cultural integration which is often touted. American culture continues to be neighborhood bound. Future study is indicated in an effort to test whether the paradigm is a valid tool for representing cultural interrelationships in the United States.
\end{abstract}

Key words: cultural neighborhoods, assimilation, force fields, diversity, multiculturalism

\section{INTRODUCTION}

These United States have rightly earned the distinction of being the world's melting pot. Emma Lazarus' poem from The New Colossus, engraved upon the base of the Statue of Liberty, articulates this place in the world (Lazarus, 1949):

Not like the brazen giant of Greek fame, With conquering limbs astride from land to land; Here at our sea-washed, sunset gates shall stand A mighty woman with a torch, whose flame Is the imprisoned lightning and her name Mother of Exiles. From her beacon-hand Glows world-wide welcome; her mild eyes command. The air-bridged harbor that twin cities frame. "Keep, ancient lands, your "storied pomp"! cries she with silent lips. "Give me your tired, your poor, Your huddled masses yearning to breathe free, The wretched refuse of your teeming shore. Send these, the homeless, tempest-tost to me, I lift my lamp beside the "golden door"! (Lazurus, 18831949)
With such powerful imagery these lines serve as a relevant discourse of our nation's immigration history. However, the continuance of that discourse has veered off course due to the unnecessary complexity of the multiculturalism debate.

For two centuries this country has developed a patchwork of populations drawn from all corners of the world. Yet, the reality of socio-economic hierarchy favors the descendents of early white Anglo-Saxon settlers. While in years since, the financial worlds have been influenced by German-Jewish émigrés in the early 20th century (Birmingham, 1968), a few other groups have been able to similarly penetrate the socioeconomic hierarchy.

Through the turmoil of the Civil Rights movement and subsequent legislation, there has been an opening up of the society but not to the extent that the pundits might assume. This discussion will instead focus on the idea that American society has not become multicultural although there is diversity in the public sphere of American society. In reality multiculturalism is a misnomer. The idea of self-contained cultural neighborhoods with all the inherent characteristics remains valid, with few exceptions. The authors

Corresponding Author: Mary Beth Leidman, Department of Communications Media, Indiana University of Pennsylvania, USA 
propose here a paradigm/model designed to graphically display a theoretical construct of these cultural neighborhoods which will be illustrated and further offered for explanation.

Problem statement: Contemporary academic discourse regarding multiculturalism has run adrift on the sandbars of various methodologies and disciplines. The field needs well-defined paradigms to accurately describe contemporary cultural experience and reality.

For the purposes of this discussion, the term diversity will be defined as a social structure or group which includes participants from varying racial, ethnic, religious and family organizations, as gender inclusive in casual or public settings. It is heterogeneous in all senses of that word. Multiculturalism will be defined as a set of social structures and groupings which include varying ethnic, religious and family organizations as well as being gender inclusive throughout the social fabric of both public and private encounters. Multiculturalism therefore by this definition is inclusively cross-cultural and intercultural by means of communications and social strata.

The proposed paradigm represents in visual terms that diversity is two-dimensional and multiculturalism is three-dimensional. The dimensions of diversity include a superficial even if sincere sharing of more outward cultural expressions such as accent born from a foreign language or even certain slang or inflections which find their path into the majority language in public places. Common among this dimension would be such Spanish expressions as "Adios" for "See you later" or "muchacho" for "friend." Hebrew and Yiddish also display movement into the general American English lexicon with sometimes less than complimentary labels. The second dimension which sometimes finds its way into the public consciousness is food. Where would American society be without ravioli, wontons, or bagels? However, as we move into the three dimensions of multiculturalism, we must acknowledge the existence of a slightly permeable membrane in neighborhoods. This membrane allows for interaction among visitors and residents, but does not permit the permeability of meaningful sharing of language, customs, food, or cultural traditions outside the perceived confines of the specific insular cultural group.

Culturalism is by nature nation-bound. It is rigid and not easily shared given neighborhood boundaries of language, food, common church or religion and comfort/informal tradition adherence. These are the limitations and the defining characteristics of cultural difference and sameness.
There are of course anomalies and other devices by which to take exception to this thought path. Among these is the idea of diversity and multiculturalism within homogeneous and self-contained societies which might be separated by any number of factors including race, geography/region and religion even within what casually appears as an intra-similar society. Examples of this include many of the South Asian nation-states such as China, Korea and Japan and also, the Middle Eastern countries such as Israel, Saudi Arabia and Egypt. However, it can be theorized that variations within these self-contained cultures do exist, given variation customs, traditions and languages similar to the differences in traditions across regions found in the United States but not to the same degree. However, for the purposes of this discussion, the ideas surrounding diversity and multiculturalism are to be limited by this thesis in application to American society in the early years of the 21 st Century.

Summary of literature: Debate surrounding this topic led to the development of this paradigm. An abundance of terminology coupled with a lack of both clarity and reflection have produced a nebulous discursive on the elements of multiculturalism and diversity. Academicians from fields such as English, Sociology, Anthropology, Communications and Library Science have contributed to and extended the debate on multiculturalism and diversity.

The notion of polycentric multiculturalism, posited to provide a way in which to make multiculturalism more accessible on global terms, serves to differentiate itself from liberal pluralism. It achieves this by embracing a radical reformulation of urban and community structures at the level of neighborhood and nation-state (Stam, 2000; Bodziany, 2008; Aldrige, 2004). Other researchers have suggested that a significant multiculturalism must include the "politics of equity, economic redistribution and social restructuring" (also referred to as critical multiculturalism) (Hartman and Gerteis, 2005). These assertions and definitions are infused with political affectations which are difficult to test empirically. Further, these opaque musings lack the theoretical clarity necessary for progressive debate.

Does multiculturalism, as a term, epistemologically differ from assimilationism? The melting pot imagery connected with multiculturalism suggests a kind of assimilation (Hartman and Gerteis, 2005; Bodziany, 2008). Assimilationism differs structurally from fragmented pluralism, which envisions the existence of encapsulated and distinct cultural communities. Whereas assimilationism is political, fragmented 
pluralism is more group-oriented and social (Hartman and Gerteis, 2005).

As a term, multiculturalism suffers from the inadequacies consistent with being used to describe and define a host of schemata. On the one hand, multiculturalism is a mere re-phrasing of cultural relativism (Bodziany, 2008). Yet, on the other hand it represents something potentially dangerous; it implies a notion that threatens the foundations of civil rights and the "regulatory power of affirmative action to embrace a notion of diversity where "all differences are equal" (Peterson, 1995). This potentially controversial view posits that diversity is wholly immutable given that as a cultural component, it is not to be haphazardly described and defined. It other words, difference and diversity seem to be positive components of society. Perhaps multiculturalism itself does not actually exist.

While diversity is apparent throughout the United States, multiculturalism often needs to be defined by or assigned to a specific context to make it real (Mannix and Neale, 2005). One study in particular found that trust is far more fleeting among counterparts of given minority groups than members of a majority (Stolle et al., 2008). Indeed, it appears that neighborhoods which are argued to be multicultural are less likely to perceive and execute interpersonal trust. The same study found that individuals who regularly interact with their neighbors are not as impacted by the perceived realities of race and ethnicity when compared to individuals without such interaction. Within Lewin's theories of Forced-Field Analysis there also lies the basis for this current thinking surrounding diversity and multiculturalism. Lewin (1992) demonstrates that change takes place within society and/or organizations in different stages, starting with the status quo which within the present discussion would be represented by the continuing and protective integrity of cultural neighborhoods. After the status quo is established and maintained, pressure(s) act upon the static situation forcing movement. After moving, there is a refreezing of position and reestablishment of a status quo. Changes in position(s) can occur quickly or slowly, once or many times as the forces dictate.

\section{Models:}

Assumptions: Within any self-sustaining culture there exists a group of characteristics which can be described as Defining Intracultural Traits (DITS). These traits define the cultural neighborhood and include (1) unity of language characteristics which encompass signifiers and signs, semiotics and semantics, verbal and nonverbal; (2) similarity in food including the foods and beverages which would be served at traditional and/or familial gatherings; (3) participation in church, religion or other ideologically-based behavior encompassing those characteristics within the realm of religion and place of worship and/or spiritual-ideological gathering ; and, (4) comfort level within the customs of a specific group signified by the familiarity and comfort level relative to the individual or group of a particular linguistics, cultural and religious background and/or ethnicity. For the purposes of this discussion they shall be referred to in order as language, food, religion/church and comfort level.

Societal pressures might suggest that selfsustaining cultures will move towards each other and share superficially out of the cultural neighborhood meeting in and forming the diverse public sector $\alpha$. In all scenarios, each cultural neighborhood is bound by these characteristics only joining in the public sphere of $\alpha$. DITS continues to be present and identifiable in all sectors reflecting varying levels of sharing and intensity of interaction. There are two distinct stages in the development of this theoretical construct. The first, "establishment and maintenance of independent selfsustaining cultural entities" represents the status quo (Fig. 1). It illustrates how distinct cultural neighborhoods independently revolve around a public diverse sphere $\alpha . \beta, \gamma, \delta$ and $\varepsilon$ all represent specific cultures and, clearly, many more such entities are present in American society. The second paradigm, "separation, intersection and characteristics of cross cultural interaction" illustrates the results of changing dynamics and movement (Fig. 2). It demonstrates that when forces change, there is change which in terms of self-sustained cultural neighborhoods results in the formation of a causal relationship between varying cultures and their DITS. This supports the train of thought that cultures within the same general society will meet, at least casually, in the public $\alpha$ sector sharing easily digestible and acceptable bits of unique cultures.

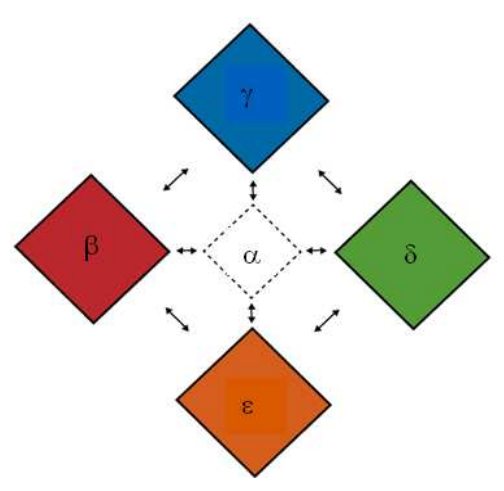

Fig. 1: Establishment and maintenance of independent self-sustaining cultural entities 


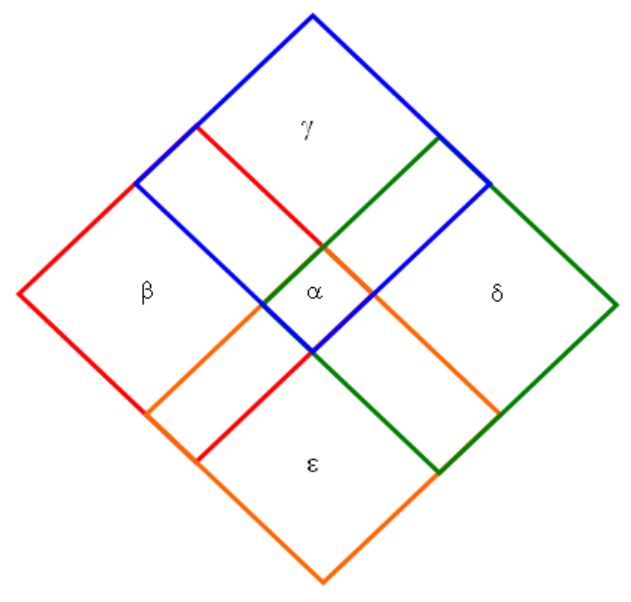

Fig. 2: Separation, intersection and characteristics of cross cultural interaction

\section{MATERIALS AND METHODS}

The theoretical construct introduced herein is based on a selected review of applicable literature and application of such social theory as found within Forced-Field Analysis as it is being applied to the study and issues surrounding diversity and multiculturalism. Isolating the Defining Intracultural Traits and hypothesizing how they currently interact as exclusionary factors rather than inclusionary factors acts as a basis for the ultimate development of the paradigm.

\section{RESULTS}

The illustrations above are both comprised of four diamonds. The researchers have used a diamond template given the related study accomplished in the field of sociology and anthropology (Griswold, 2008). However, this paradigm differs given its inclusion of language. Within the construct of a universe of SelfSustaining Entities, one observes distinct cultural neighborhoods, each containing to some degree a unique combination and intensity of DITS.

The cultural neighborhoods are described as the diamonds $\beta, \gamma, \delta$ and $\varepsilon$. They are not static. They can and do change position on an angle moving in towards each other eventually meeting in a public sphere. When the paradigm has shifted sufficiently, a new model results, exhibiting characteristics of a new relationship between cultures. In the model describing Cross Cultural Interaction, the intersecting kaleidoscope diamond in the Center $(\alpha)$ is the result of the area. $\beta, \gamma$, $\delta$ and $\varepsilon$ each continue to represent a unique and self- sustaining culture. They all continue to support unique cultural profiles only intermixing in the $\alpha$ room.

Indeed, the model supports the idea of developing a post- $\alpha$ diamond for each self-sustaining extant culture in the United States as the paradigm shifts. Diversity exists in the $\alpha$ sector, where the intersection takes place. This is the public sector; the workplace, schools, free access settings such as museums. Within $\alpha$, there is what can be described as casual sharing of culture such as holiday trappings, common religious knowledge, foods which might find periodic, momentary acceptance and perhaps some smattering of casual language as it applies to the setting (greetings, thank you). Not to be misunderstood, these public settings are diverse and reflect the richness of the American patchwork of cultures. Even to the point that it can be accepted that decisions and decision-making patterns are at least partially influenced by the sometimes selfculturally referenced inclusion of a variety of backgrounds and experiences.

Within the $\beta, \gamma, \delta$ and $\varepsilon$ sectors independent culture sustains itself separating by exclusive language, food, church/religion and comfort level. To be more specific, American sub-cultures exist reflecting the myriad of nation states that have sent citizens to US soil. Therefore, the integrity of the culture is buoyed and the free sharing is lessened.

\section{DISCUSSION}

It is possible to hypothesize what this model will resemble as the $\beta, \gamma, \delta$ and $\varepsilon$ diamonds push into $\alpha$. There are two theories. The first is that as true multiculturalism increases, as displayed by an enlarging of the $\alpha$ sector, the other diamonds will by balance become smaller. In another view, it is possible that the outside diamonds will become smaller; simply stated, the $\alpha$ sector will remain the same size but increase in density. The density might reflect a true interweaving and creation of a common culture based on a melding of language, food, church and comfort level. Of these, the most likely to remain chauvinistic is the church/religion piece due to dogma. The religion/church characteristic will work against the realization of true multiculturalism because of inherent, independent dogma separating and maintaining itself and its integrity. The paradigm becomes threedimensional as more aspects of culture are shared across both the horizontal and vertical axes of DITS. The more intimate or open DITS becomes, the more truly multicultural become the interactions and communications. As the status quo of Cultural 
Neighborhoods continues, the two-dimensional paradigm remains in force.

Examination, inclusion and analysis of media and its analysis also support this model's validity at the present time. A future study will examine the model in an effort to test whether it is a viable tool to aid in the understanding of multiculturalism and diversity. Within an incremental approach to validating this theoretical construct, the researchers will create and administer a survey based on a qualitative research design. The survey will seek responses which will test the theoretical construct introduced here.

\section{CONCLUSION}

When will multiculturalism become a reality? How can it be effectively visualized? How long can cultures remain self-sustaining? The answers to these questions are interconnected. Cultures will remain self-sustaining as long as there are links to the parenting culture and a working knowledge of native language exists in the participants of that particular culture, or cultural stratum. True multiculturalism will increase in the United States when cultures and peoples actually grow further away from the hegemonic culture taking pieces of the home cultures generationally and absorb the strongest pieces thereby moving into the $\alpha$ sphere. The problems and challenges pertaining to sustaining language, culture and tradition are daunting. It is the maintenance of the cultural neighborhood which often acts as the cohesive element in holding basic family units together in the light of everyday societal pressures working to upset that balance by forming the larger unified multicultural $\alpha$ sphere. Yet, within the United States, the formidable pressures work together forming a unique force field which at once pushes the society together and presently holds the neighborhood as distinct units. The end to this story has yet to be written as American society continues to play out the scenario so eloquently chiseled on the welcoming arms of Lady Liberty.

\section{REFERENCES}

Aldrige, M.G., 2004. What is the Basis of American Culture? In: Intercultural Communication: A Global Reader, F.E. Jandt, (Ed.). Sage, Thousand Oaks, CA, ISBN: 13: 978 076192899, pp: 84-98.

Birmingham, S., 1968. Our Crowd. Syracuse University Press, Syracuse, NY., ISBN: 13: 97808156-04112, pp: 7-27.
Bodziany, M., 2008. Clash of cultures and identity: Sociological aspects of multiculturalism in the age of social changes. Cult.-Historic. Psychol., 4: 76-81. http://psyjournals.ru/en/kip/2008/n4/Bodziany.sht $\mathrm{ml}$

Griswold, W., 2008. Cultures and Societies in a Changing World. 3rd Ed., Sage, Thousand Oaks, CA., ISBN: 13: 9781412961264, pp: 30-38.

Hartman, D. and J. Gerteis, 2005. Dealing with diversity: Mapping multiculturalism in sociological terms. Sociol.. Theor., 23: 218-240. DOI: 10.111/j.0735-2751.2005.00251.x

Lewin, K., 1992. Force field analysis. In: Leadership Roles and Management Functions, Marquis, B. and C. Huston (Eds.)., 6th Edn., Philadelphia: Lippincott, Williams, and Wilkins. ISBN: 9780781772464, pp: 22-25.

Jandt, F.E., 2007. An introduction to intercultural communication: Identities in a global community 5th ed., Sage, Thousand Oaks, CA., ISBN: 13: 978076198478, pp: 10-15.

Lazarus, E., 1949. The new colossus. In: The World of Emma Lazarus Schocken Books, Jacob, H. (Ed.). New York, ISBN: 155111285x, pp: 3.

Mannix, E. and M.A. Neale, 2005. What differences make a difference? The promise and reality of diverse teams in organizations. Psychol. Sci. Public Interest, 6: 31-55. DOI: 10.1111/j.15291006.2005.00022.x

Peterson, L., 1995. Multiculturalism: Affirmative or negative action? Library J., 120: 30-33.

Stam, R., 2000. Eurocentrism, Polycentrism and Multicultural Pedagogy: Film and the quincentennial. In: American Cultural Studies: A Reader, J. Hartley and R.E. Pearson (Eds.). Oxford University Press, New York, ISBN: 13: 01-97842542548, pp: 373-382.

Stolle, D., S. Soroka and R. Johnston, 2008. When does diversity erode trust? Neighborhood diversity, interpersonal trust and the mediating effect of social interactions. Politic. Stud., 56: 57-75. DOI: 10.1111/j.1467-9248.2007.00717.x 